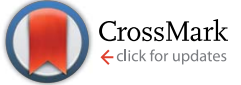

Cite this: J. Mater. Chem. A, 2017, 5, 1516

Received 25th October 2016 Accepted 5th December 2016

DOI: $10.1039 / c 6 t a 09229 b$

www.rsc.org/MaterialsA

\section{Hierarchical porous carbon with ordered straight micro-channels templated by continuous filament glass fiber arrays for high performance supercapacitors $\uparrow$}

\begin{abstract}
Dedong Jia, ${ }^{a}$ Xin Yu, ${ }^{a}$ Hua Tan, ${ }^{b}$ Xuequan Li, ${ }^{b}$ Feng Han, ${ }^{\star c}$ Linlin Li ${ }^{\star a}$ and Hong Liu*ab
Hierarchical porous carbon with highly ordered straight micro-channels was prepared though a facile melt vacuum infiltration method using continuous filament glass fiber arrays as the template and glucose as the precursor. The as-prepared carbon material shows high specific surface areas up to $1880 \mathrm{~m}^{2} \mathrm{~g}^{-1}$ profited from the unique structure of straight micro-channels. A fine pore structure is formed in the channel wall through $\mathrm{KOH}$ activation after the removal of the glass fiber array. Electrochemical evaluation of the carbon material indicates that the hierarchical porous carbon exhibits a high specific capacitance of $283 \mathrm{~F} \mathrm{~g}^{-1}$ at a current density of $0.25 \mathrm{~A} \mathrm{~g}^{-1}$ with an alkaline electrolyte $(6 \mathrm{M} \mathrm{KOH})$ in a threeelectrode system. It also demonstrates excellent cycling stability with a capacity retention of $88.5 \%$ over 10000 cycles at a high current density of $6 \mathrm{~A} \mathrm{~g}^{-1}$. These exciting results demonstrate a very simple and low-cost method for large-scale preparation of electrode materials for supercapacitors.
\end{abstract}

\section{Introduction}

In response to resource depletion and environmental pollution, researchers have been making enormous efforts to search for high-performance, low-cost, sustainable and environmentally friendly energy storage solutions. ${ }^{1}$ Besides lithium-ion batteries, supercapacitors have attracted tremendous attention due to their high power density, excellent charge and discharge properties and efficient electrical energy delivery in heavy-duty applications..$^{2-5}$ The functional mechanism for supercapacitors relies on two different phenomena: (1) double layer charging at the interface of the electrode/electrolyte, referred to as electrochemical double layer capacitance, and (2) reversible redox reactions at the electrode surface, known as pseudocapacitance. ${ }^{6}$ For pseudo-capacitors, the energy is stored through a reversible redox reaction of the electroactive species. Electrically conducting polymers ${ }^{7}$ and transition metal oxides (binary or ternary) ${ }^{8-12}$ with high energy density are the widely explored electrode materials for pseudo-capacitors. However, these materials display either poor stability or poor electrical properties, which

${ }^{a}$ Beijing Institute of Nanoenergy and Nanosystems, Chinese Academy of Sciences, National Center Nanoscience and Technology (NCNST), Beijing 100083, China. E-mail: lilinlin@binn.cas.cn

${ }^{b}$ State Key Laboratory of Crystal Material, Shandong University, Jinan 250100, PR China.E-mail: hongliu@sdu.edu.cn

'Institute of Engineering Thermodynamics, German Aerospace Center, Stuttgart 70569, Germany. E-mail: feng:han@dlr.de

$\dagger$ Electronic supplementary information (ESI) available. See DOI: $10.1039 /$ c6ta09229b limit their practical application. ${ }^{13}$ The commercially available supercapacitors are electrochemical double layer capacitors (EDLCs) which are conventionally based on carbon materials, such as activated carbon, ${ }^{14-17}$ carbon nanotubes, ${ }^{18}$ graphenes, ${ }^{19}$ carbon aerogels ${ }^{20}$ and carbide-derived carbons. ${ }^{21}$

To achieve high electrochemical performance of supercapacitors, research efforts have been focused on synthesis of nanostructured carbon materials with a high surface area, good chemical stability, appropriate wettability and high electronic conductivity. ${ }^{22-26}$ In order to enhance the porosity and specific surface area, the carbon materials are usually activated to introduce more active sites. In general, the activation of carbon materials can be performed in two ways: (1) physical activation with different oxidizing gases, such as air, $\mathrm{O}_{2}, \mathrm{CO}_{2}$, steam or their mixture, and (2) chemical activation with $\mathrm{KOH}, \mathrm{NaOH}, \mathrm{H}_{3} \mathrm{PO}_{4}$, $\mathrm{ZnCl}_{2}$, or other chemicals at high temperature. ${ }^{1}$ In fact, the performance of supercapacitors is not only related to the specific surface area, but also to the pore size and the pore distribution of the carbon materials. Previous research studies have showed that pores with size variation often exist simultaneously in active carbon, including macropores (larger than $50 \mathrm{~nm}$ ), mesopores $\left(2\right.$ to $50 \mathrm{~nm}$ ) and micropores (smaller than $2 \mathrm{~nm}$ ). ${ }^{27}$ These pores normally have random size distribution and small pores that are often not permeable for electrolytes. As a result, only a part of the surface is effectively utilized and most of them do not contribute to the double-layer capacitance of the electrode. ${ }^{28-30}$ Accordingly, ordered mesoporous carbon with a well-defined pore size distribution and connected pore channels is considered to be a more effective electrode material for supercapacitors instead of 
conventional active carbon. ${ }^{31-34}$ For instance, mesoporous $\mathrm{SiO}_{2}$ templates are applied to synthesize structurally fine-tuned mesoporous carbon, such as $\mathrm{CMK}-3$ derived from $\mathrm{SiO}_{2}$ (SBA-15). ${ }^{31}$ Prepared through this way, the carbon materials with a high surface area often have micropores and mesopores, which are beneficial to electrolyte transport but unfavourable for retaining the electrolyte. I. Nongwe et al. applied $\mathrm{SiO}_{2}$ spheres as templates for the preparation of macroporous carbon, which could be beneficial for holding more electrolyte. ${ }^{35}$ However, these macropores that are formed through etching away the $\mathrm{SiO}_{2}$ spheres are normally not continuously connected. The separated pores could be favourable for retaining the electrolyte but cannot provide enough continuous pathways for the electrolyte transport. Therefore, it is necessary to synthesis a carbon with continuous channels which can provide highways for the electrolyte transport. In addition, there are some disadvantages which cannot be ignored about those hard templates mentioned above, such as the complicated preparation steps and enormous time and energy consumption during the synthesis. Moreover, the high cost and complex process make the preparation of such porous carbon on a large-scale unrealistic and limit its further application. In order to accelerate the commercialization of supercapacitors for energy applications, it is necessary to develop simplified methods for fabrication of structurally ordered porous carbon and replace the expensive $\mathrm{SiO}_{2}$ templates with low-cost substitutive materials.

Continuous filament glass fibers are inexpensive and promising alternative templates for further development of costeffective functional carbon material manufacturing techniques. Normally, the diameter of continuous filament glass fibers is about 5-7 $\mu \mathrm{m}$, which could be suitable for preparing templated hierarchical porous carbon with ordered straight micro-channels. Herein, we report a facile and novel melt vacuum infiltration method for the preparation of such hierarchical porous carbon materials, in which a bundled continuous filament glass fiber array is applied as the template and glucose is used as the precursor. The ordered straight micro-channels in the prepared carbonized material are favourable for the transportation and retaining of the electrolyte. Through $\mathrm{KOH}$ activation, micropores and small mesopores are formed on the wall of micro-channels, forming a hierarchical porous carbon material. ${ }^{25,36}$ Tested with a three-electrode configuration, the as-prepared carbon material demonstrates excellent gravimetric capacitance up to $283 \mathrm{~F} \mathrm{~g}^{-1}$ in $6 \mathrm{M} \mathrm{KOH}$ electrolyte. It is remarkable that both the template (continuous filament glass fibers) and the precursor (glucose) are inexpensive commercialized products for many decades. Based on the facile and low-cost melt vacuum infiltration synthesis process, this work may bring a feasible solution for mass production of high-performance carbon-based electrode materials for supercapacitors in the near future.

\section{Experimental section}

\section{Chemicals}

All materials were purchased from commercial sources and used as received without further purification. The continuous filament glass fibers (88 $\mathrm{g} \mathrm{km}^{-1}, 5-7 \mu \mathrm{m}$ in diameter) were purchased from Tianjin Zhongtian Junda Glassfiber Pros Co.

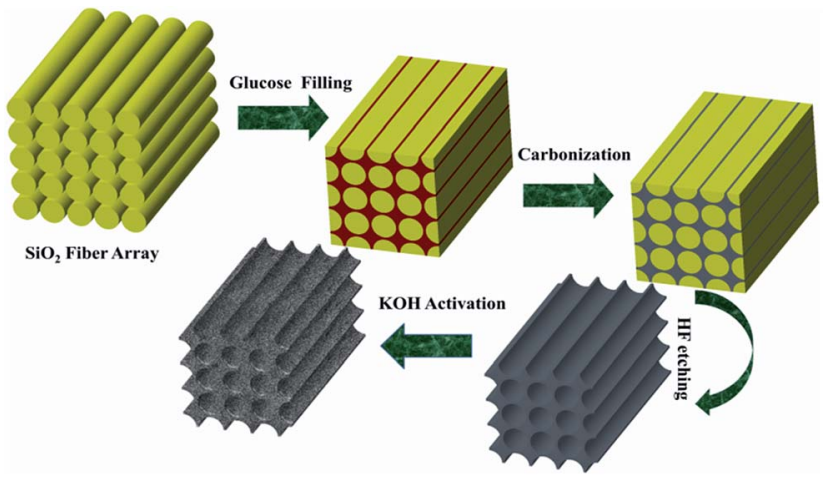

Scheme 1 Schematic of the synthesis process of GTSDC-900 in this work.

Ltd. and D-glucose was purchased from Sinopharm Chemical Reagent Co. Ltd.

\section{Material fabrication}

The continuous filament glass fibers were cut into $5 \mathrm{~cm}$ in length and tightly bundled together to form a glass fiber array. Mixed with an appropriate amount of glucose powder, the fiber array was placed in a covered glass beaker and heated up to $180^{\circ} \mathrm{C}$ in a vacuum drying chamber. In the process, molten glucose infiltrated into the gaps of the glass fiber array due to the capillary force. After two hours, the sample was taken out and cooled down to form a rigid solid hybrid precursor composite, which consisted of the glass fiber array and solidified glucose. The glucose on the glass fiber array was carbonized through a heat treatment at $800{ }^{\circ} \mathrm{C}$ for 3 hours with a heating rate of $5{ }^{\circ} \mathrm{C}$ $\min ^{-1}$ under $\mathrm{N}_{2}$ gas flow. Then the samples were immersed in $20 \mathrm{wt} \% \mathrm{HF}$ solution for 5 days to etch away the glass fibers completely to obtain a carbon material with ordered straight microchannels. For simplicity, this carbon material is abbreviated as GTSDC (glucose templated by $\mathrm{SiO}_{2}$-fiber derived carbon) in this paper. The GTSDC samples were chemically activated in order to get enhanced electrochemical properties. The samples were immersed into $6 \mathrm{M} \mathrm{KOH}$ solution with a weight ratio of $1: 3$ (GTSDC : KOH) and dried at $100{ }^{\circ} \mathrm{C}$ to evaporate the water. Subsequently, the dried samples were thermally treated at activation temperature for 2 hours under $\mathrm{N}_{2}$ gas flow with a heating rate of $5{ }^{\circ} \mathrm{C} \min ^{-1}$ in a tubular furnace. The activation temperature was chosen as $700{ }^{\circ} \mathrm{C}, 800{ }^{\circ} \mathrm{C}, 900{ }^{\circ} \mathrm{C}$ and $1000{ }^{\circ} \mathrm{C}$ (corresponding samples were abbreviated as GTSDC-700, GTSDC-800, GTSDC-900 and GTSDC-1000, respectively). After cooling down to room temperature, the $\mathrm{KOH}$ residue was quickly removed with $1 \mathrm{M} \mathrm{HCl}$ solution, and then was washed repeatedly with deionized water until the $\mathrm{pH}$ value reached 7. Finally, the samples were dried at $80{ }^{\circ} \mathrm{C}$ in an ambient atmosphere for 12 hours. The preparation process of GTSDC-900 is illustrated in Scheme 1. As a comparison, two reference samples were also prepared. One reference sample was prepared by carbonizing the condensed glucose directly at $800{ }^{\circ} \mathrm{C}$, abbreviated as GDC (glucose derived carbon). Another reference sample was GDC activated at $900{ }^{\circ} \mathrm{C}$ with the same $\mathrm{KOH}$ activation process used for GTSDC, abbreviated as GDC-900. 


\section{Material characterization}

Scanning electron microscopy (SEM) images were obtained on a SEM-a HITACHI S-8020 at $5 \mathrm{kV}$ for surface morphology investigation. High-resolution transmission electron microscopy (HRTEM) images were acquired from a JEOL JEM 2100 microscope with an operating voltage of $200 \mathrm{kV} . \mathrm{N}_{2}$ adsorptiondesorption analysis was carried out on a Micrometrics ASAP 2020 HD88 to evaluate the porosity and pore size distribution. The degas condition was set to 4 hours at $250{ }^{\circ} \mathrm{C}$ under a vacuum of $500 \mu \mathrm{mHg}(\sim 0.67 \mathrm{mbar})$, and all adsorptiondesorption measurements were carried out at liquid nitrogen temperature. The X-ray diffraction (XRD) measurements were carried out on a Bruker D8 Advance powder X-ray diffractometer with $\mathrm{Cu}-\mathrm{K} \alpha$ radiation $(\lambda=0.15406 \mathrm{~nm})$. The $2 \theta$ angular region was between $10^{\circ}$ and $85^{\circ}$, and the scanning rate was set at $6^{\circ} \min ^{-1}$ with a step of $0.02^{\circ}$ for data acquisition. Raman spectra were acquired from a Dilor XY microspectrometer with $532 \mathrm{~nm}$ laser excitation.

\section{Electrode fabrication and electrochemical measurements}

The electrochemical behaviour of all carbon samples was investigated in a three-electrode cell configuration and a twoelectrode cell configuration. In the three-electrode configuration, the prepared electrode with a size of $1 \mathrm{~cm} \times 1 \mathrm{~cm}$ was used as the working electrode, an $\mathrm{Ag} / \mathrm{AgCl}$ electrode functioned as the reference electrode, and a platinum foil with a size of $2 \mathrm{~cm} \times$ $2 \mathrm{~cm}$ served as the counter electrode. The working electrode was prepared by mixing the as-prepared carbon material sample, carbon black and poly(vinylidene fluoride) (PVDF) with a weight ratio of $80: 10: 10$. PVDF was previously dissolved in $N$-methyl pyrrolidinone to form $0.02 \mathrm{~g} \mathrm{~mL}^{-1}$ solution. After stirring for 12 hours, the mixture was coated on a nickel foil with a size of $1 \mathrm{~cm} \times 1 \mathrm{~cm}$, and dried at $120{ }^{\circ} \mathrm{C}$ for 10 hours to remove NMP. Then the dried material was slightly pressed, and the mass loading of the active material on the nickel foil was weighed. The three-electrode system was tested in $6 \mathrm{M} \mathrm{KOH}$ electrolyte solution. The two-electrode fastener-type symmetric supercapacitor cells were assembled with a pair of stainless steel disks as the current collector and a piece of glassy fiber paper as the separator. A solution of $6 \mathrm{M} \mathrm{KOH}$ was used as the electrolyte.

The cyclic voltammetry (CV), electrochemical impedance spectroscopy (EIS) measurements (potential: $0 \mathrm{~V}$, amplitude: $5 \mathrm{mV}$, frequency: $100 \mathrm{mHz}$ to $100 \mathrm{KHz}$ ) and the galvanostatic charge-discharge measurements were performed by using a CHI 660 Electrochemical Workstation (CH Instruments, China). The capacitance from CV curves was calculated by the equations $C^{*}=\int I \mathrm{~d} t / m V$ for the three-electrode cells and $C=4 \int I \mathrm{~d} t / m V$ for the two-electrode cells, where $I$ is the constant current, $V$ is the voltage window, and $m$ is the mass of the active electrode material. The specific capacitance from galvanostatic charge-discharge was calculated by using the formulas $C^{*}=I t / m V$ for the three-electrode cells and $C=4 I t / m V$ for the two-electrode cells, where $I$ is the constant current, $V$ is the voltage window, $m$ is the total mass for both carbon electrodes, and $t$ is the discharge time. For the two-electrode system, the energy density was calculated by the formulas $E=\left(C V^{2}\right) / 2$ and $P=E / t$, where $C$ is the specific capacitance from galvanostatic charge-discharge testing and $t$ is the discharge time.

\section{Results and discussion}

The microstructure of the as-synthesized samples at each step is characterized by SEM. The continuous filament glass fibers with a uniform diameter about 5-7 $\mu \mathrm{m}$ have a smooth surface (Fig. S1a-d $\dagger$ ). Through the melt infiltration process under vacuum at $180^{\circ} \mathrm{C}$, the apertures of the bundled glass fiber array can be completely filled with glucose (Fig. S1e-h $\dagger$ ), and form a hybrid precursor of the glucose filled bundled bulk glass fiber array. After the carbonization of the glucose, the sample transformed into a hybrid composite of carbon filled bundled glass fibers without much morphological change (Fig. S1i-l $\dagger$ ). The glass fibers in the hybrid composite were removed through the subsequent chemical etching process, and the carbon material with uniform and straight ordered microchannels was obtained, as shown in Fig. S1m-p. $\dagger$ It is obvious that the microchannels are well-aligned and parallel to each other forming a highly ordered array. From Fig. S1o and $p, \dagger$ we can find that the diameter of the channels in the porous carbon is approximately $5 \mu \mathrm{m}$, which is identical to the morphology and size of the continuous filament glass fiber template. The thickness of the channel wall is about $1 \mu \mathrm{m}$, which is determined by the gap between adjacent fibers. The surface of inner and outer channel walls is smooth and uniform without obvious pores or pits. Fig. S2 $\uparrow$ shows the images of samples at different synthesis steps, i.e. the precursor composite of glucose impregnated bundled glass fibers (Fig. S2a $\dagger$ ), hybrid material of carbon filled bundled glass fibers (Fig. S2b $\dagger$ ), and porous carbon with ordered channels (GTSDC) (Fig. S2c $\dagger$ ). As seen in Fig. S2, $\dagger$ the sample always maintains its cylindrical macroscopic shape during the preparation process.

SEM images of the KOH activated carbon material (GTSDC) at $700-1000{ }^{\circ} \mathrm{C}$ are shown in Fig. 1. Fig. $1 \mathrm{a}$ is the top view of the sample of GTSDC-700. After activation, the microchannels of the carbon material keep the ordered characteristics and a similar diameter without collapse or distortion (Fig. 1a and b). In the images with higher resolution (Fig. 1c and d), some pits on the surface of the channel wall are found in the area with defects. When the temperature increases to 800 (Fig. $1 \mathrm{~g}$ and $\mathrm{h}$ ), 900 (Fig. $1 \mathrm{k}$ and $\mathrm{l}$ ) and $1000{ }^{\circ} \mathrm{C}$ (Fig. 10 and p), the surface of the channel wall becomes more rough, and is full of open and interconnected pores. However, it is difficult to observe the micropores distributed on the channel wall due to the resolution limitation of the SEM. Additionally, fractures are observed on the channels of the samples activated at high temperature (Fig. 1e and $\mathrm{f}$ for GTSDC-800, $\mathrm{i}$ and $\mathrm{j}$ for GTSDC-900, $\mathrm{m}$ and $\mathrm{n}$ for GTSDC-1000). It can be deduced that the reaction between carbon and $\mathrm{KOH}$ may become more intensive as the activation temperature increases. As expected, hierarchical structured carbon materials with a high specific surface area could be obtained through the filament glass fiber templated $\mathrm{KOH}$ 


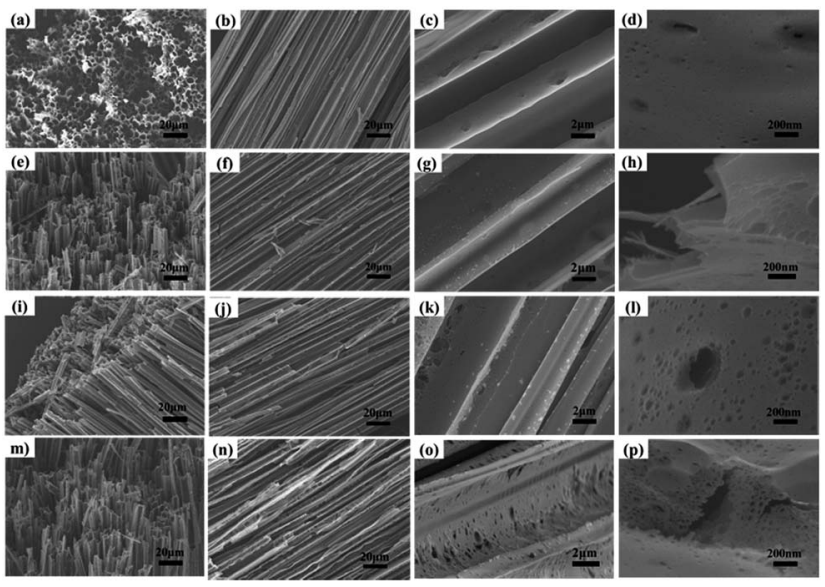

Fig. 1 SEM images of GTSDC activated at different temperatures: GTSDC-700 (a-d), GTSDC-800 (e-h), GTSDC-900 (i-l), and GTSDC$1000(m-p)$.

activation process. The highly ordered straight microchannels are derived from the glass fiber array, and fine pores formed on the wall of the micro-channels originate from the $\mathrm{KOH}$ activation process. As a comparison, the morphology of carbon derived from the glucose direct carbonization process (GDC) and then activated by $\mathrm{KOH}$ at $900{ }^{\circ} \mathrm{C}$ (GDC-900) was also characterized by SEM (Fig. S3 $\uparrow$ ). It is found that the surface of GDC is rough and full of pores after $\mathrm{KOH}$ activation (GDC-900), which is similar to the morphology of the surface on the channel wall of GTSDC-900. However, no ordered micro-channels can be found without using a glass fiber template.

The structure and morphology of crushed powders of all four carbon samples activated at different temperatures were further investigated by high-resolution transmission electron microscopy (HRTEM). The TEM image of GTSDC-700 with lower resolution shows that the sample has a uniform morphology (Fig. 2a). From the HRTEM micrograph (Fig. 2b), it can be observed that numerous nanoparticles about $2-3 \mathrm{~nm}$ in size homogeneously distribute in the crushed amorphous carbon. When the activation temperature increases to $800{ }^{\circ} \mathrm{C}$ (Fig. $2 \mathrm{c}$ and d), the size and distribution of the micropores in GTSDC800 have no obvious difference compared with those of the sample activated at $700{ }^{\circ} \mathrm{C}$. With further increase of the activation temperature to $900{ }^{\circ} \mathrm{C}$ (Fig. 2e and f), the pore size of
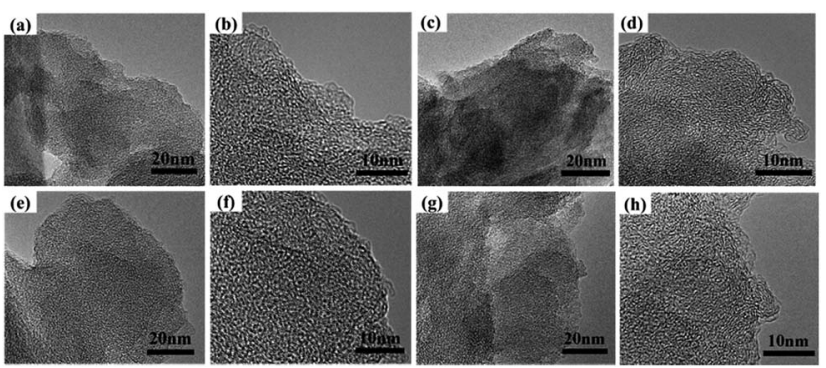

Fig. 2 HRTEM images of GTSDC activated at different temperatures: GTSDC-700 ( $a$ and b), GTSDC-800 ( $c$ and d), GTSDC-900 (e and f), and GTSDC-1000 ( $\mathrm{g}$ and $\mathrm{h}$ ).
GTSDC-900 also does not change obviously, but most of the pores are connected together. As the activation temperature increases to $1000{ }^{\circ} \mathrm{C}$, the sample becomes more transparent under irradiation of electrons, and some lattice fringes can be observed in HRTEM images (Fig. $2 \mathrm{~g}$ and $\mathrm{h}$ ), indicating the formation of graphene at this temperature. The following XRD and Raman analysis could reach the same conclusion that higher temperature can lead to higher graphitization, which is also supported by the appearance of a 2D peak of GTSDC-1000 in Raman spectra. The HRTEM image of GTSDC without KOH activation is shown in Fig. $\mathrm{S} 4 \uparrow$ for comparison. It is mostly characterized by disordered carbon and few crystalline areas which is similar to GTSDC-700 and GTSDC-800.

To assess the phase transformation of the samples during the preparation process, X-ray diffraction (XRD) patterns of all samples are shown in Fig. 3a. The characteristic peaks located at $2 \theta$ of $25^{\circ}$ can be assigned to the (002) diffraction of graphitic carbon, and the peak at about 43 corresponds to (101) diffraction of solid carbon materials. ${ }^{37,38}$ Particularly, for GDC and GTSDC carbon materials without $\mathrm{KOH}$ activation, the broad and low intensity peaks around $25^{\circ}$ suggest the poor graphitic crystallinity. After activation by $\mathrm{KOH}$, the peaks with higher intensity are observed for GDC-900 and GTSDC-900, indicating that the degree of graphitization enhances by $\mathrm{KOH}$ activation at higher temperature. In the XRD patterns of GTSDC-700, GTSDC800 , GTSDC-900 and GTSDC-1000, it can be found that the intensity of the peak at a $2 \theta$ position of around $25^{\circ}$ gradually increases with increasing activation temperature, indicating that the graphitization improves.

To further characterize the graphitization of the samples, Raman spectra of all the carbon materials before and after activation were recorded. Fig. 3b depicts the Raman spectra of all the samples. All the spectra show very similar patterns with two broad peaks at about $1580 \mathrm{~cm}^{-1}$ and $1350 \mathrm{~cm}^{-1}$. The peak at $1580 \mathrm{~cm}^{-1}$ (G-band) is attributed to the vibration of $\mathrm{sp}^{2}$-bonded carbon atom in a $2 \mathrm{D}$ hexagonal lattice, namely, the
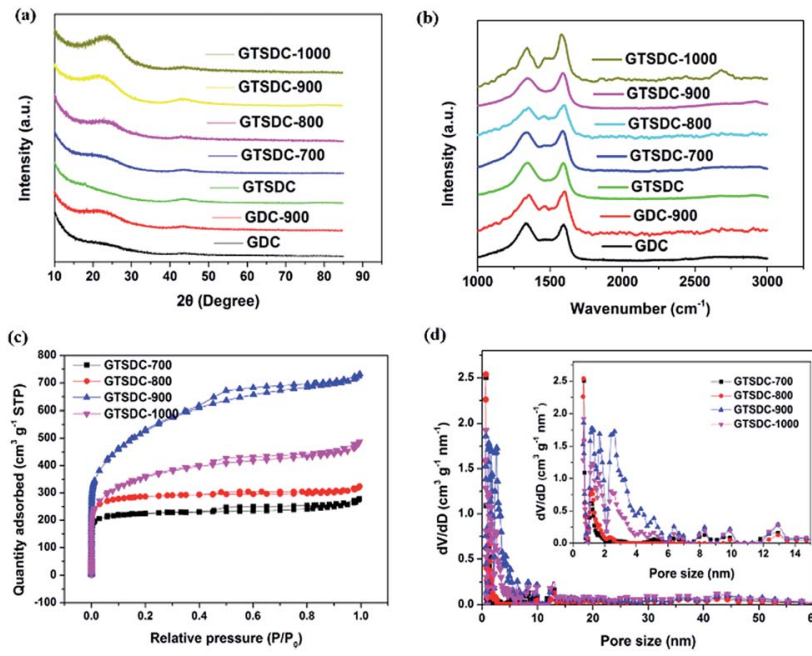

(d)

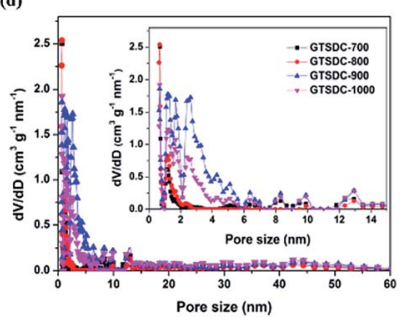

Fig. 3 The XRD patterns (a), Raman spectra (b), nitrogen adsorptiondesorption isotherms (c) and DFT pore-size distribution curves (d) of carbon samples. 
Table 1 The intensity ratio of the D-band to the G-band and surface area and pore structure of the as-prepared carbon materials

\begin{tabular}{|c|c|c|c|c|c|}
\hline Samples & $I_{\mathrm{D}} / I_{\mathrm{G}}{ }^{a}$ & $S_{\mathrm{BET}}^{b}\left[\mathrm{~cm}^{3} \mathrm{~g}^{-1}\right]$ & Micropore volume $\left[\mathrm{cm}^{3} \mathrm{~g}^{-1}\right]$ & Mesopore volume $\left[\mathrm{cm}^{3} \mathrm{~g}^{-1}\right]$ & Total pore volume ${ }^{c}\left[\mathrm{~cm}^{3} \mathrm{~g}^{-1}\right]$ \\
\hline GTSDC-700 & 0.97 & 759 & 0.36 & 0.12 & 0.43 \\
\hline GTSDC-800 & 0.91 & 971 & 0.29 & 0.13 & 0.50 \\
\hline GTSDC-1000 & 0.70 & 1259 & 0.20 & 0.50 & 0.75 \\
\hline
\end{tabular}

${ }^{a} I_{\mathrm{G}}$ and $I_{\mathrm{D}}$ are the integral intensities of the $\mathrm{D}$ and $\mathrm{G}$ band. ${ }^{b}$ Specific surface area calculated by the Brunauer-Emmett-Teller (BET) equation. ${ }^{c}$ The total pore volume was determined from the amount of nitrogen adsorbed at a relative pressure of 0.99 .

stretching modes of $\mathrm{C}=\mathrm{C}$ bonds of typical graphite, while the peak at $1350 \mathrm{~cm}^{-1}$ (D-band) is associated with vibration of carbon atoms with dangling bonds in plane terminations of the disordered graphite and is related to the defects and disorders of the structures in carbon material..$^{39,40}$ The relative intensities of these two lines $\left(I_{\mathrm{D}} / I_{\mathrm{G}}\right)$ depend on the type of graphitic material and reflect the degree of graphitization. The intensity ratios of the $\mathrm{D}$ and $\mathrm{G}$ bands for all the carbon samples are listed in Table 1. For GDC and GTSDC, the intensity of the D band is almost as high as the $\mathrm{G}$ band, and the $I_{\mathrm{D}} / I_{\mathrm{G}}$ ratio is about 1.03 and 1.01, which indicate the poor graphitization concentration. On the other hand, the similar Raman bands for GDC and GTSDC show that the continuous filament glass fiber array template has negligible impact on the crystal structures of carbon. For GDC-900 and GTSDC-900, the lower intensity at $1350 \mathrm{~cm}^{-1}$ (D band) and the peak with high intensity at $1580 \mathrm{~cm}^{-1}$ (G band) were observed, reflecting a higher graphitization concentration after activation by $\mathrm{KOH}$ at $900{ }^{\circ} \mathrm{C}$. As shown in Table 1 , the $I_{\mathrm{D}} / I_{\mathrm{G}}$ ratio of GDC-900 and GTSDC-900 decreases to 0.91 and 0.88 , respectively. As the activation temperature increases from 700 to $1000{ }^{\circ} \mathrm{C}$, the $I_{\mathrm{D}} / I_{\mathrm{G}}$ ratio of GTSDC-700, GTSDC-800, GTSDC-900 and GTSDC-1000 decreases to $0.97,0.91,0.88$ and 0.70 , respectively. This indicates that higher temperature can enhance the degree of graphitization in the carbon materials. Impressively, the GTSDC-1000 not only shows the D and G band, but also displays the $2 \mathrm{D}$ peak at about $2700 \mathrm{~cm}^{-1}$, which is believed to be the characteristic peak of graphene. ${ }^{41}$ It can be expected that disordered carbon can provide more active sites for charge storage, and the graphene framework can improve the conductivity. The optimal carbon based supercapacitor electrode should keep a balance of the ratio of disordered carbon and ordered graphitized carbon.

The pore-size characterization of GTSDC activated at different temperatures was carried out by measuring the nitrogen adsorption/desorption isotherms. From the isotherms (Fig. 3c), all of them show a type $I$ curve at relative pressure $P / P_{0}$ $<0.90$ according to IUPAC classification, demonstrating adsorption in micropores. ${ }^{42}$ The steep increase in the adsorbed volume at very low relative pressure $\left(P / P_{0}<0.05\right)$ results from the abundant micropores in solids. ${ }^{43}$ For GTSDC-900 and GTSDC1000 , the curve exhibits a small rise at $0.5-0.9 P / P_{0}$, showing the existence of mesopores. This result can also be demonstrated by the pore size distribution (PSD) curves as shown in Fig. 3d. As for samples GTSDC-900 and GTSDC-1000, the PSD curves exhibit obvious peaks at about $0.7,1.2,1.6,3,13$ and $44 \mathrm{~nm}$. It indicates that these two samples have both mesopores with a size of 3, 14 and $44 \mathrm{~nm}$ and ultramicropores with a size of $0.7 \mathrm{~nm}$ and other micropores (1.2 and $1.6 \mathrm{~nm}) .{ }^{44}$ Compared with GTSDC-900, sample GTSDC-1000 has more micropores than mesopores. As for samples GTSDC-700 and GTSDC-800, the most obvious peaks of PSD curves lie in 0.7 and $1.2 \mathrm{~nm}$, indicating that these two carbon samples have ultramicropores with a size of about $0.7 \mathrm{~nm}$ and other micropores $(1.2 \mathrm{~nm})$ but with very few mesopores. Therefore, sample GTSDC-900 has the ideal size distribution compared with the three other samples. It is well known that ideal electrochemical capacitor materials should have a hierarchical porous structure containing macropores for ion-buffering, mesopores for ion transport and micropores for enhancement of charge storage. ${ }^{45}$ It could be predicated that GTSDC-900 should possess the best electrochemical performance among the prepared samples. In addition, the specific surface area and pore volumes of the carbon materials are summarised in Table 1 . As the activation temperature varies from 700,800 to $900{ }^{\circ} \mathrm{C}$, the corresponding specific surface area enhances from 759.1, 971.2 to $1880 \mathrm{~m}^{2} \mathrm{~g}^{-1}$. With further increase of the activation temperature to $1000{ }^{\circ} \mathrm{C}$, the specific area of the sample GTSDC-1000 drops to $1259 \mathrm{~m}^{2}$ $\mathrm{g}^{-1}$. It can be seen that the PSD curve of GTSDC-1000 is much lower than that of GTSDC-900 in the range of 1-5 nm, indicating that a large number of pores with the size of 1-5 nm disappear when the temperature increases from 900 to $1000{ }^{\circ} \mathrm{C}$. Therefore, we believed that at $1000{ }^{\circ} \mathrm{C}$, too much carbon reacted with $\mathrm{KOH}$ and led to part of small pores collapsing, hence resulting in the decrease of the surface area. ${ }^{44}$ Therefore, the optimum activation temperature for GTSDC is $900{ }^{\circ} \mathrm{C}$, and GTSDC-900 not only possesses the highest specific surface area, but also the highest total pore volume $\left(1.13 \mathrm{~m}^{2} \mathrm{~g}^{-1}\right)$, which makes it to be the potential electrodes with excellent electrochemical performance.

The performance of the supercapacitors based on all the carbon material samples was measured in $6 \mathrm{M} \mathrm{KOH}$ electrolyte using a three-electrode configuration. Cyclic voltammetry (CV) is utilized to estimate the electrochemical behaviour of all the carbon materials, and the results are depicted in Fig. 4. The CV curves of GDC, GDC-900, GTSDC and GTSDC-900 are acquired at a scan rate of $100 \mathrm{mV} \mathrm{s}^{-1}$ and compared in Fig. 4a. Small area and highly distorted CV curves of GDC and GTSDC indicate poor electrochemical performances. After $\mathrm{KOH}$ activation at $900{ }^{\circ} \mathrm{C}$, the area of CV curves of GDC-900 and GTSDC-900 is 
(a)

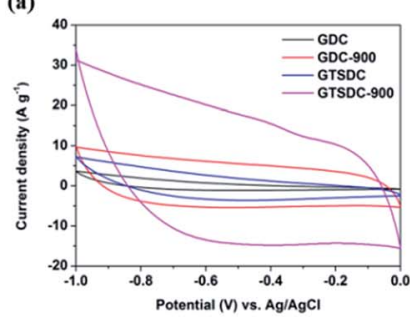

(e)

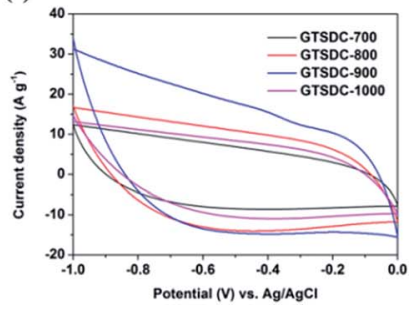

(b)

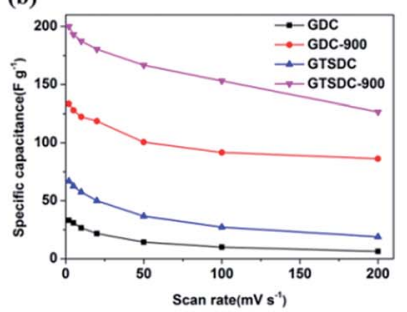

(f)

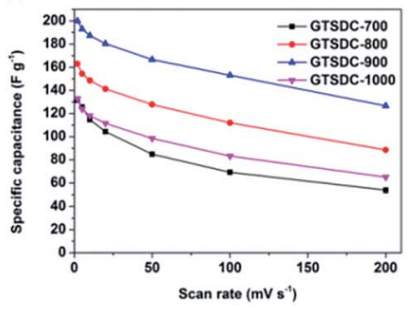

(c)

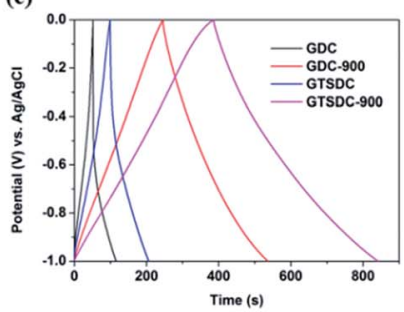

(g)

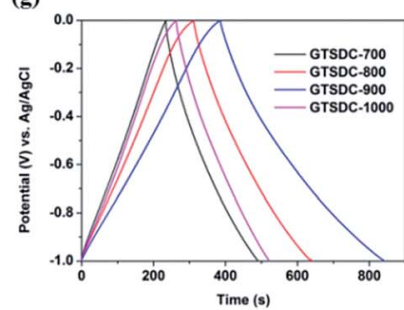

(d)

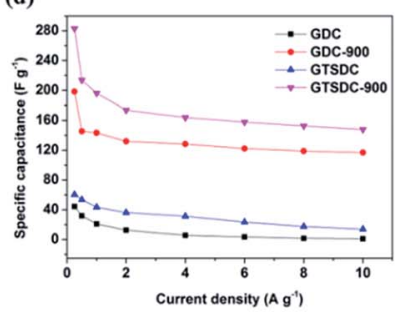

(h)

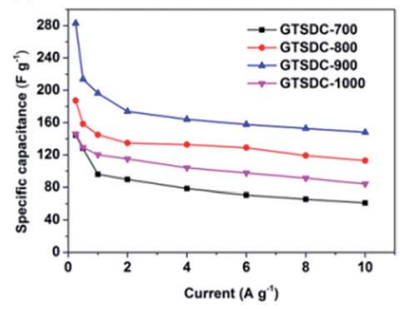

Fig. $4 \mathrm{CV}$ curves of all carbon electrodes at $100 \mathrm{mV} \mathrm{s}^{-1}$ rates (a and e); specific capacitance of carbon electrodes at various scan rates (b and f); galvanostatic charge-discharge curves under $0.5 \mathrm{~A} \mathrm{~g}^{-1}$ ( $\mathrm{c}$ and g); specific capacitance of carbon electrodes at different current densities ( $\mathrm{d}$ and $\mathrm{h}$ ).

much larger than that of GDC and GTSDC, respectively, and the CV curves display a nearly rectangular shape, which indicates the ideal capacitance performance and high energy storage efficiency due to the $\mathrm{KOH}$ activation. It is noteworthy that current density of the GTSDC and GTSDC-900 is much higher than that of GDC and GDC-900, respectively. The results demonstrate that the GTSDC and GTSDC-900 have a higher charge storage capacity than GDC and GDC-900. Considering the completely different structure between GTSDC-900 and GDC-900, as well as between GTSDC and GDC, it is deduced that the highly ordered straight channels existing in GTSDC and GTSDC-900 would be beneficial for the electrolyte osmosis and its diffusion in the whole electrode material. Fig. $4 \mathrm{~b}$ shows the gravimetric specific capacitance of the four carbon samples, as a result of $\mathrm{CV}$ testing with the different scan rates in the range of 2 to $200 \mathrm{mV} \mathrm{s}^{-1}$. According to the results, the values of the specific capacitance of unactivated carbon GDC and GTSDC are 33.2 and $66.9 \mathrm{~F} \mathrm{~g}^{-1}$ at a low scan rate of $2 \mathrm{mV} \mathrm{s}^{-1}$, while only 6.4 and $18.9 \mathrm{~F} \mathrm{~g}^{-1}$ of the capacitance remain when the scan rate increases to $200 \mathrm{mV} \mathrm{s}^{-1}$, indicating that the GDC and GTSDC not only have poor electrochemical performance, but also exhibit undesirable rate capacitance. For GDC-900 and GTSDC900 , the specific capacitances at a scan rate of $2 \mathrm{mV} \mathrm{s}^{-1}$ are 200 and $133.5 \mathrm{~F} \mathrm{~g}^{-1}$, respectively, and keep 126.6 and $86.2 \mathrm{~F} \mathrm{~g}^{-1}$ at $200 \mathrm{mV} \mathrm{s}^{-1}$. It indicates that the $\mathrm{KOH}$ activation should have improved the rate capability. In order to further investigate the electrochemical behaviour of the four carbon specimens, the galvanostatic charge-discharge curves at a current density of $0.5 \mathrm{~A} \mathrm{~g}^{-1}$ are recorded, and shown in Fig. 4c. The electrodes of GDC and GTSDC display distorted triangular shapes, which indicate low coulombic efficiency. Obviously, the electrodes of GDC-900 and GTSDC-900 present a nearly isosceles triangular shape with good symmetry, illustrating high coulombic efficiency. The calculated specific capacitances of GDC and GTSDC are only 31.9 and $53.6 \mathrm{~F} \mathrm{~g}^{-1}$, while higher values of 145.6 and $213.8 \mathrm{~F} \mathrm{~g}^{-1}$ are observed for GDC-900 and GTSDC-900, respectively. It indicates that the straight ordered channels derived from glass fibers and $\mathrm{KOH}$ activation can significantly improve the capacitive performance of the as-prepared carbon material. Fig. 4d summarizes the gravimetric specific capacitance of four samples as a result of galvanostatic chargedischarge curves. For instance, notably, the specific capacitance value of $283 \mathrm{~F} \mathrm{~g}^{-1}$ at a current density of $0.25 \mathrm{~A} \mathrm{~g}^{-1}$ is observed, which is much higher than that of the electrode made from other carbon materials as reported in previous literature, such as carbons derived from human hair (about $264 \mathrm{~F} \mathrm{~g}^{-1}$ ), ${ }^{47}$ carbon xerogels obtained from glucose-graphene oxide hybrids (143$\left.239 \mathrm{~F} \mathrm{~g}^{-1}\right),{ }^{48}$ carbons derived from carbon dioxide activated glucose $\left(158 \mathrm{~F} \mathrm{~g}^{-1}\right){ }^{49}$ and carbon and graphene composites $(150-210 \mathrm{~F}$ $\left.\mathrm{g}^{-1}\right) \cdot{ }^{50,51}$ In addition, it is found that the specific capacitances of GTSDC-900 and GTSDC are always higher than those of GDC900 and GDC at various current densities in the range of 0.25 to $10 \mathrm{~A} \mathrm{~g}^{-1}$. The results obtained from the galvanostatic chargedischarge curve are in complete accordance with the results obtained from CV testing. The effect of $\mathrm{KOH}$ activation temperature on the capacitance performance is also studied in detail. Fig. 4e displays the CV curves of the GTSDC activated at different temperatures at a scan rate of $100 \mathrm{mV} \mathrm{s}^{-1}$. All four samples, i.e. GTSDC-700, GTSDC-800, GTSDC-900 and GTSDC1000 , exhibit a quasi-rectangular shape, which indicates excellent electrochemical reversibility. The current density of $\mathrm{KOH}$ activated GTSDC increases with increasing activation temperature from 700 to $900{ }^{\circ} \mathrm{C}$, and drops at $1000{ }^{\circ} \mathrm{C}$. The specific capacitances are shown in Fig. 4f. Activated with $\mathrm{KOH}$ at temperatures of 700 and $1000{ }^{\circ} \mathrm{C}$, the specific capacitances of GTSDC-700 and GTSDC-1000 are only 131 and $132.9 \mathrm{~F} \mathrm{~g}^{-1}$ at the scan rate of $2 \mathrm{mV} \mathrm{s}^{-1}$. By contrast, the GTSDC-900 possesses a much higher specific capacitance of $200 \mathrm{~F} \mathrm{~g}^{-1}$, suggesting that the suitable activation temperature is critical for the improvement of specific capacitance. As the scan rate increases to $100 \mathrm{mV} \mathrm{s}^{-1}$, the capacitance of GTSDC-900 decreases to $153.1 \mathrm{~F} \mathrm{~g}^{-1}$. The same phenomenon occurs for other carbon samples 
activated at different temperatures, i.e. GTSDC-700, GTSDC-800 and GTSDC-1000. The specific capacitance decreased in an acceptable level with the increase of scan rate, and it suggests good rate capability for all the activated carbon materials. The galvanostatic charge-discharge curves at a current density of $0.5 \mathrm{~A}$ $\mathrm{g}^{-1}$ and the specific capacitances calculated from the galvanostatic charge-discharge curves at different current densities are shown in Fig. $4 \mathrm{~g}$ and $\mathrm{h}$, respectively. The obtained specific capacitance values are $128.1,162.5,213.8$, and $129.3 \mathrm{~F} \mathrm{~g}^{-1}$ at a current density of $0.5 \mathrm{~A} \mathrm{~g}^{-1}$ for GTSDC-700, GTSDC-800, GTSDC-900, and GTSDC-1000, respectively. Obviously, the GTSDC-900 shows the best specific capacitive performance compared to the samples activated at other temperatures, which is consistent with the result calculated from the CV curve. The supercapacitive performance of GTSDC-900 is further investigated, and Fig. $\mathrm{S} 4 \uparrow$ shows the $\mathrm{CV}$ curves at different scan rates and galvanostatic charge-discharge curves at different current densities. With the scan rate varying from 2 to $200 \mathrm{mV} \mathrm{s}^{-1}$, CV curves of GTSDC-900 always keep the rectangular shape, demonstrating a nearly ideal capacitive behaviour. At the same time, the charge and discharge part of GTSDC-900' galvanostatic charge-discharge curves is symmetric at different current densities ranging from 0.25 to $10 \mathrm{~A} \mathrm{~g}^{-1}$. In general, the electrochemical performance of all porous carbon samples was tested by $\mathrm{CV}$ at different scan rates and galvanostatic charge/ discharge at different current densities. Therefore, the specific capacitance calculated from CV curves and galvanostatic charge-discharge curves is listed in Tables $1 \mathrm{~S}$ and $2 \mathrm{~S}, \dagger$ respectively.

The performance of the supercapacitor based on the GTSDC-900 sample was measured by using a two-electrode symmetrical system in $6 \mathrm{M} \mathrm{KOH}$ aqueous electrolyte. Fig. 5a shows the $\mathrm{CV}$ curves at different scan rates ranging from 2 to $1000 \mathrm{mV} \mathrm{s}^{-1}$. The rectangular shape of the $\mathrm{CV}$ is observed even
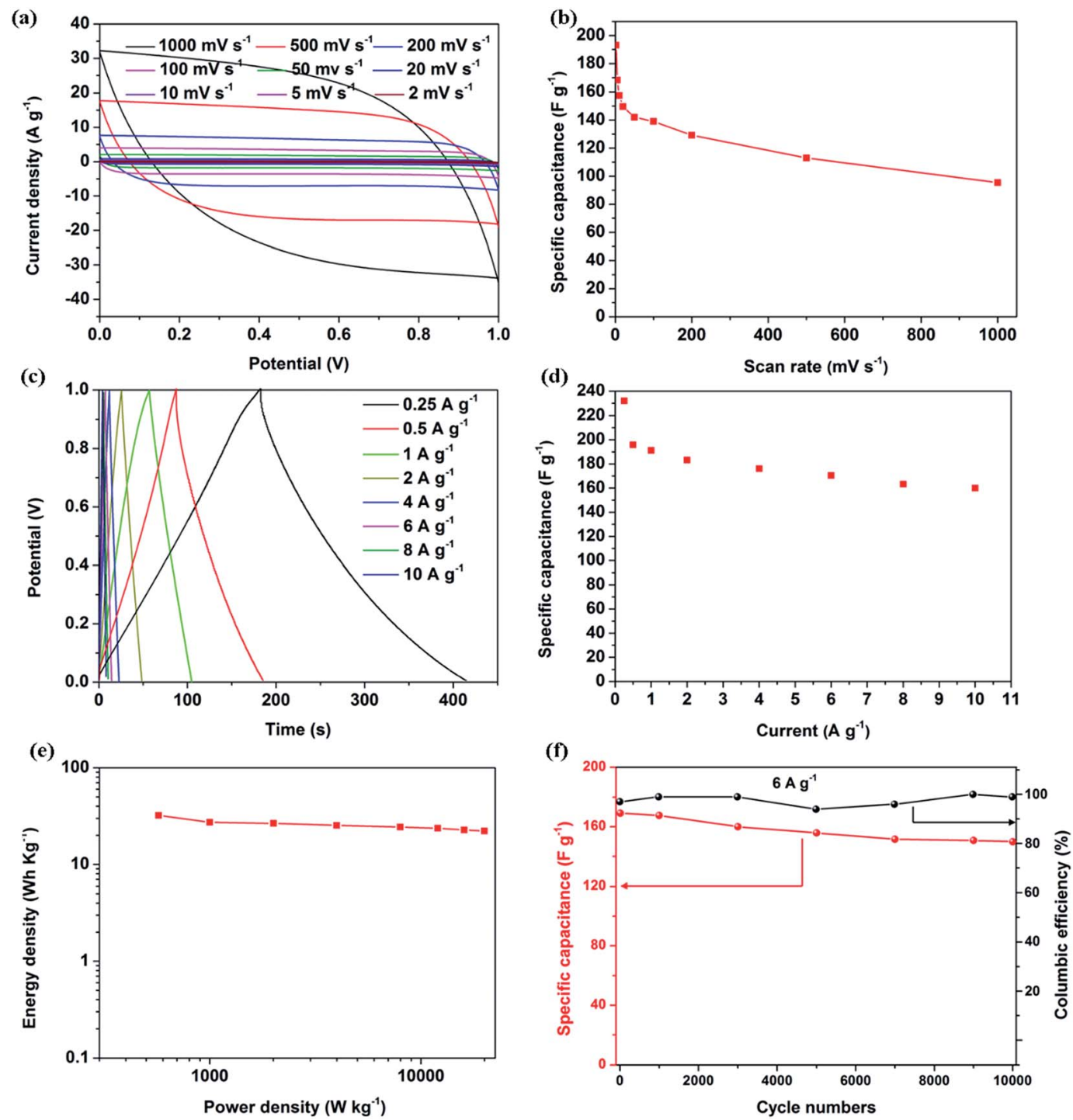

Fig. 5 CV curves of the GTSDC-900 symmetric supercapacitor (a) and calculated specific capacitance at various scan rates (b); galvanostatic charge/discharge curves of the symmetric supercapacitor (c) and calculated specific capacitance at various current densities (d); Ragone plots (e); specific capacitance (red) and coulombic efficiency (black) of GTSDC-900 symmetric supercapacitor at $6 \mathrm{~A} \mathrm{~g}^{-1}$ over $_{10} 000 \mathrm{cycles}$ (f). 
at $500 \mathrm{mV} \mathrm{s}^{-1}$, indicating a very fast and efficient charge transfer. ${ }^{50}$ As shown in Fig. 5b, the highest specific capacitance value reaches $193.2 \mathrm{~F} \mathrm{~g}^{-1}$ at $2 \mathrm{mV} \mathrm{s}^{-1}$, and the value remains at $113 \mathrm{~F} \mathrm{~g}^{-1}$ as the scan rate increases to $200 \mathrm{mV} \mathrm{s}^{-1}$, suggesting good rate capability of GTSGC-900. As displayed in Fig. 5c, the IR drop for this symmetric supercapacitor is relatively low, indicating that the two-electrode cell has low internal resistance due to fast charge transfer and ion diffusion. Calculated by the galvanostatic charge-discharge curves, the specific capacitances versus different current density are summarized in Fig. 5d. The specific capacitance is measured with a high value of $202.3 \mathrm{~F} \mathrm{~g}^{-1}$ at $0.25 \mathrm{~A} \mathrm{~g}^{-1}$, and still maintains $160 \mathrm{~F} \mathrm{~g}^{-1}$, even when the current density increases to $10 \mathrm{~A} \mathrm{~g}^{-1}$, i.e. $79.2 \%$ capacitance retention as the current density increased by 40 times. The symmetrical supercapacitor made from GTSDC-900 exhibits excellent rate capability. Moreover, the power density and energy density of the symmetric cell are shown in a Ragone plot (Fig. 5e). The energy density can reach as high as $32.2 \mathrm{~W} \mathrm{~h} \mathrm{~kg}^{-1}$ at a power density of $0.5 \mathrm{~kW} \mathrm{~kg}^{-1}$ and $22.2 \mathrm{~W} \mathrm{~h} \mathrm{~kg}^{-1}$ at a power density of $20 \mathrm{~kW} \mathrm{~kg}^{-1}$, which is higher than those of previously reported carbon symmetric supercapacitors in aqueous electrolytes, such as graphene-based carbon aerogels ( 20 to $27.4 \mathrm{~W} \mathrm{~h} \mathrm{~kg}^{-1}$ ), ${ }^{53}$ templated active carbon (2.7 to $\left.4.2 \mathrm{~W} \mathrm{~h} \mathrm{~kg}^{-1}\right),{ }^{54}$ petroleum-coke-derived active carbon ( 8 to $\left.10 \mathrm{~W} \mathrm{~h} \mathrm{~kg}^{-1}\right),{ }^{55}$ sunflower-seed-shell-derived active carbon ( 3 to $\left.6 \mathrm{~W} \mathrm{~h} \mathrm{~kg}^{-1}\right),{ }^{56}$ mesophase-based active carbon ( 0.45 to $2 \mathrm{~W}$ $\left.\mathrm{h} \mathrm{kg}{ }^{-1}\right),{ }^{57}$ cherry-stone-derived active carbon $(0.9$ to $2 \mathrm{~W}$ $\mathrm{h} \mathrm{kg}^{-1}$ ), ${ }^{58}$ waste-coffee-ground-derived active carbon (5 to $40 \mathrm{~W}$ $\left.\mathrm{h} \mathrm{kg}^{-1}\right)^{59}$ and polyfurfuryl-alcohol-derived active carbon (32 W $\left.\mathrm{h} \mathrm{kg}^{-1}\right) .{ }^{60}$ The energy density of our device compared to the values of other reported devices is shown in Fig. S5 $\dagger$ in detail.

In order to assess the cycling stability of GTSDC-900 for supercapacitor applications, the galvanostatic charge-discharge was conducted at a constant current density of $6 \mathrm{~A} \mathrm{~g}^{-1}$ for 10000 cycles. Fig. $5 \mathrm{f}$ shows that the capacitance retention can reach $88.5 \%$ with a moderate decrease from 170.4 to $150.8 \mathrm{~F} \mathrm{~g}^{-1}$, indicating the excellent cycling stability of GTSDC-900 even at high current density. Additionally, the coulombic efficiency is about $97 \%$ (10th cycle), 99\% (1000th cycle), 99\% (3000th cycle), $94 \%$ (5000th cycle), 96\% (7000th cycle), 100\% (9000th cycle), and $99 \%$ (10 000th cycle), respectively. Therefore, the symmetric supercapacitor always has nearly perfect coulombic efficiency over 10000 cycles. Electrochemical impedance spectroscopy (EIS) was employed for further study of the electrochemical performance of the carbon specimens (Fig. 6). Generally, linear
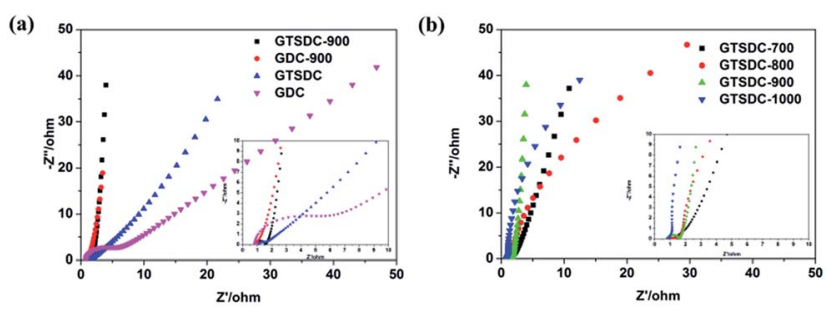

Fig. 6 The Nyquist plots of all the carbon specimens showing imaginary part versus real part of impedance in $6 \mathrm{M} \mathrm{KOH}$ aqueous solution. The inset magnifies its expanded high-frequency region. curves in the low frequency region can indicate the capacitive performance, while the semicircles in the high frequency region represent the charge transfer resistance. Fig. 6a shows the impedance curves obtained from four different samples GDC, GDC-900, GTSDC and GTSDC-900 at different frequencies ranging from 0.01 to $100 \mathrm{kHz}$. Apparently, the GTSDC-900 possesses the steepest slope of line (the phase angle about $87^{\circ}$ ) and the smallest diameter of the semicircle $(0.64 \Omega)$, indicating a nearly ideal capacitance and the smallest charge transfer resistance. As a comparison, the phase angle values of the other samples are much smaller than those of GTSDC-900. Additionally, GTSDC-900 and GDC-900 display a relatively low equivalent series resistance (ESR) of about $0.81 \Omega$ and $0.79 \Omega$, which are lower than those of GTSDC $(1.07 \Omega)$ and GDC $(0.83 \Omega)$. These results can be explained by the disordered carbon content in the carbon specimens. When the glucose was only carbonized at $800{ }^{\circ} \mathrm{C}$, the main phase of the material is amorphous carbon. Thus the electrode made from GTSDC and GDC shows higher internal resistance. Part of amorphous carbon was etched away via the $\mathrm{KOH}$ activation process; therefore, the internal resistance of GTSDC-900 and GDC-900 are smaller than those of the unactivated carbon materials. The impedance curves of the samples activated at different temperatures can be seen in Fig. $5 \mathrm{~b}$. The equivalent series resistance decreases in the order of GTSDC-1000 (0.80) < GTSDC-900 (0.81) < GTSDC-800 (1.01) and GTSDC-700 (1.01). Hence, it is believed that with an increase of activation temperature, the relative content of graphene increases, leading to improved conductivity, which is consistent with the XRD and Raman results. Therefore, the highest electrochemical performance of GTSDC-900 should originate from: (1) hierarchical porous structure with well-defined pore distribution and ordered straight micro-channels; (2) large surface area and active sites derived from $\mathrm{KOH}$ activation; (3) improved conductivity related to the graphene content formed inside carbon materials.

\section{Conclusions}

In this work, a precursor made of glucose, templated by continuous filament glass fiber arrays, has been processed through a method combining melt vacuum infiltration, carbonization and $\mathrm{KOH}$ activation process. A unique hierarchical porous carbon with highly ordered straight micro-channels and well-defined porosity on the channel-wall has been synthesised. The carbon material shows an ultrahigh specific surface area of $1880 \mathrm{~m}^{2} \mathrm{~g}^{-1}$ and exhibits an excellent specific capacitance of $283 \mathrm{~F} \mathrm{~g}^{-1}$ at $0.25 \mathrm{~A} \mathrm{~g}^{-1}$. The symmetric supercapacitor employing two electrodes and the best performed carbon materials synthesized in this work displays high cycling stability with $88.5 \%$ capacitance retention over 10000 cycles. Moreover, the energy densities of $32.2 \mathrm{~W} \mathrm{~h} \mathrm{~kg}^{-1}$ at a power density of $0.5 \mathrm{~kW} \mathrm{~kg}^{-1}$ and $22.2 \mathrm{~W} \mathrm{~h} \mathrm{~kg}^{-1}$ at a power density $20 \mathrm{~kW} \mathrm{~kg}{ }^{-1}$ are also demonstrated. Compared with the reference specimen, outstanding electrochemical performance delivered by the synthesized carbon could be attributed to the unique microstructure with highly ordered straight microchannels and well-defined porosity on the channel wall, which 
is beneficial for retaining and transportation of the electrolyte. More importantly, both the glass fiber template and the glucose precursor are inexpensive industrial products. Therefore, the current work provides a promising route for mass production of high performance and low-cost supercapacitor materials.

\section{Acknowledgements}

This work was supported by the National Nature Science Foundation of China (No. 81471784, No. 31270022, and No. 51372142), the Youth Innovation Promotion Association of the Chinese Academy of Sciences (2015023), and the "Thousands Talents" program for pioneer researcher and his innovation team, China.

\section{References}

1 M. Sevilla and R. Mokaya, Energy Environ. Sci., 2014, 7, 12501280.

2 R. F. Service, Science, 2006, 313, 902.

3 J. R. Miller and P. Simon, Science, 2008, 321, 651-652.

4 P. Balaya, Energy Environ. Sci., 2008, 1, 645-654.

5 J. Baxter, Z. Bian, G. Chen, D. Danielson, M. S. Dressehaus, A. G. Fedorov, T. S. Fisher, C. W. Jones, E. Maginn, U. Kortshagen, A. Manthiram, A. Nozik, D. R. Rolison, T. Sands, L. Shi, D. Sholl and Y. Wu, Energy Environ. Sci., 2009, 2, 559-588.

6 R. H. Baughman, A. A. Zakbidov and W. A. de Heer, Science, 2002, 297, 787-792.

7 M. Vujkovic, N. Gavriov, I. Pasti, J. Krstic, J. Travas-Sejdic, G. Ciric-Marjanovic and S. Mentus, Carbon, 2013, 64, 472486.

8 J. Jiang, Y. Li, J. Liu, X. Huang, C. Yuan and X. W. Lou, Adv. Mater., 2012, 24, 5166-5180.

9 C. Yuan, H. B. Wu, Y. Xie and X. W. Lou, Angew. Chem., Int. Ed., 2014, 53, 1488-1504.

10 G. Zhang and X. W. Lou, Adv. Mater., 2013, 25, 976-979.

11 G. Yuan, L. Yang, L. Hou, L. Shen, X. Zhang and X. W. Lou, Energy Environ. Sci., 2012, 5, 7883-7887.

12 S. Ding, T. Zhu, J. S. Chen, Z. Wang, C. Yuan and X. W. Lou, J. Mater. Chem. A, 2011, 21, 6602-6606.

13 G. Yu, X. Xie, L. Pan, Z. Bao and Y. Cui, Nano Energy, 2013, 2, 213-234.

14 J. Zhou, X. Yuan, W. Xing, W. Si and S. Zhou, Carbon, 2010, 48, 2765-2772.

15 Z. B. Wen, Q. T. Qu, Q. Gao, X. W. Zheng, Z. H. Hu, Y. P. Wu, Y. F. Liu and X. J. Wang, Electrochem. Commun., 2009, 11, 715-718.

16 X. He, P. Ling, J. Qiu, M. Yu, X. Zhang, C. Yu and M. Zheng, J. Power Sources, 2013, 240, 109-113.

17 J. Wang, L. Shen, B. Ding, P. Nie, H. Deng, H. Dou and X. Zhang, RSC Adv., 2014, 4, 7538-7544.

18 J. Kalupson, D. Ma, C. A. Randall, R. Rajagopalan and K. Adu, J. Phys. Chem. C, 2014, 118, 2943-2952.

19 Z. Xing, B. Wang, W. Gao, C. Pan, J. K. Halsted, E. S. Chong, J. Lu, X. Wang, W. Luo, C. H. Chang, Y. Wen, S. Ma, K. Amine and X. Ji, Nano Energy, 2015, 11, 600-610.
20 N. Liu, J. Shen and D. Liu, Microporous Mesoporous Mater., 2013, 167, 176-181.

21 P. Gao, W. Tsai, B. Daffos, P. Taberna, C. R. Perez, Y. Gogotsi, P. Simon and F. Favier, Nano Energy, 2015, 12, 197-206.

22 D.-W. Wang, F. Li, M. Liu, G. Q. Lu and H.-M. Cheng, Angew. Chem., Int. Ed., 2008, 120, 379-382.

23 P. Simon and Y. Gogotsi, Nat. Mater., 2008, 7, 845-854.

24 J. Huang, B. G. Sumpter and V. Meunier, Angew. Chem., Int. Ed., 2008, 47, 520-524.

25 M. Liu, J. Qian, Y. Zhao, D. Zhu, L. Gan and L. Chen, J. Mater. Chem. A, 2015, 3, 11517-11526.

26 D. Zhu, Y. Wang, W. Lu, H. Zhang, Z. Song, D. Luo, L. Gan,

M. Liu and D. Sun, Carbon, 2017, 111, 667-674.

27 IUPAC, Pure Appl. Chem., 1972, 31, 578.

28 S. M. Saufi and A. F. Ismail, Carbon, 2004, 42, 241-259.

29 T. Kyotani, Carbon, 2000, 38, 269-286.

30 S. R. S. Prabaharan, R. Vimala and Z. Zainal, J. Power Sources, 2006, 161, 730-736.

31 J. Lee and J. Kim, Adv. Mater., 2006, 18, 2073-2094.

32 J. Lee, S. Yoon, T. Hyeon, S. M. Oh and K. B. Kim, Chem. Commun., 1999, 2177-2178.

33 S. Yoon, J. Lee, T. Hyeon and S. M. Oh, J. Electrochem. Soc., 2000, 147, 2507-2512.

34 D. D. Zhou, Y. J. Du, Y. F. Song, Y. G. Wang, C. X. Wang and Y. Y. Xia, J. Mater. Chem. A, 2013, 1, 1192-1200.

35 I. Nongwe, V. Ravat, R. Meijboom and N. Coville, Appl. Catal., A, 2016, 517, 30-38.

36 J. Wang and S. Kaskel, J. Mater. Chem. A, 2012, 22, 2371023725.

37 L. Qie, W.-M. Chen, Z.-H. Wang, Q.-G. Shao, X. Li, L.-X. Yuan, X.-L. Hu, W.-X. Zhang and Y.-H. Huang, Adv. Mater., 2012, 24, 2047-2050.

38 F. Su, C. K. Poh, J. S. Chen, G. Xu, D. Wang, Q. Li, J. Lin and X. W. Lou, Energy Environ. Sci., 2011, 4, 717-724.

39 Y. Wang, F. Su, C. D. Wood, J. Y. Lee and X. S. Zhao, Ind. Eng. Chem. Res., 2008, 47, 2294-2300.

40 M. Liu, X. Ma, L. Gan, Z. Xu, D. Zhu and L. Chen, J. Mater. Chem. A, 2014, 2, 17107-17114.

41 D. Graf, F. Molitor, K. Ensslin, C. Stamper, A. Jungen, C. Hierold and L. Wirtz, Nano Lett., 2007, 7, 238-242.

42 K. Sing, D. Everett, R. Haul, L. Moscou, R. Pierotti, J. Rouque and T. Siemieniewska, Pure Appl. Chem., 1985, 57, 603-619.

43 Y. Zhao, M. Liu, L. Gan, X. Ma, D. Zhu, Z. Xu and L. Chen, Energy Fuels, 2014, 28, 1561-1568.

44 W. Lu, M. Liu, L. Miao, D. Zhu, X. Wang, H. Duan, Z. Wang, L. Li, Z. Xu, L. Gan and L. Chen, Electrochim. Acta, 2016, 205, 132-141.

45 M. Zhi, C. Xiang, J. Li, M. Li and N. Wu, Nanoscale, 2013, 5, 72-88.

46 P. Hao, Z. Zhao, J. Tian, H. Li, Y. Sang, G. Yu, H. Cai, H. Liu, C. P. Wong and A. Umar, Nanoscale, 2014, 6, 12120-12129.

47 W. Si, J. Zhou, S. Zhang, S. Li, X. Wei and S. Zhou, Electrochim. Acta, 2013, 107, 397-405.

48 M. Enterria, F. J. Martin-Jimeno, F. Suarez-Garcia, J. I. Paredes, M. F. R. Pereira, J. I. Martins, A. MartinezAlonso, J. M. D. Tascon and J. L. Figueiredo, Carbon, 2016, 105, 474-483. 
49 T. Tooming, T. Thomberg, H. Kurig, A. Janes and E. Lust, J. Power Sources, 2015, 280, 667-677.

50 G. Zhang, T. Wang, X. Yu, H. Zhang and H. Duan, Nano Energy, 2013, 2, 586-594.

51 J. Yan, T. Wei, B. Shao, F. Ma, Z. Fan, M. Zhang, C. Zheng, Y. Shang, W. Qian and F. Wei, Carbon, 2010, 48, 1731-1737.

52 Y. Li, Z. Li and P. K. Shen, Adv. Mater., 2013, 25, 2474-2480.

53 P. Hao, Z. Zhao, Y. Leng, J. Tian, Y. Sang, R. I. Bought, C. P. Wang, H. Liu and B. Yang, Nano Energy, 2016, 15, 9-23.

54 W. Xing, C. C. Huang, S. P. Zhuo, X. Yuan, G. Q. Wang, D. Hulicova-Jurcakova, Z. F. Yang and G. Q. Lu, Carbon, 2009, 47, 1715-1722.

55 X. He, Y. Geng, J. Qiu, M. Zheng, S. Long and X. Zhan, Carbon, 2010, 48, 1662-1669.
56 X. Li, W. Xing, S. Zhuo, J. Zhou, F. Li, S.-Z. Qiao and G.-O. Lu, Bioresour. Technol., 2011, 102, 1118-1123.

57 V. Ruiz, C. Balanco, R. Santamaria, J. M. Ramos-Fernandez, M. Martinez-Escandell, A. Sepulveda-Escribano and F. Rodriguez-Reinoso, Carbon, 2009, 47, 195-200.

58 M. Olivares-Marin, J. A. Fernandez, M. J. Lazaro, C. Fernandez-Gonzalez, A. Macisa-Garcia, V. GemezSerrano, F. Stoeckli and T. A. Centeno, Mater. Chem. Phys., 2009, 114, 323-327.

59 T. E. Rufford, D. Hulicova-Jurcakova, E. Fiset, Z. Zhu and G. Q. Lu, Electrochem. Commun., 2009, 11, 974-977.

60 V. Ruiz and A. G. Pandolfo, Electrochim. Acta, 2010, 55, 74957500 . 